\title{
The mitochondrial genomes of the ciliates Euplotes minuta and
} Euplotes crassus

\author{
Rob M de Graaf ${ }^{1}$, Theo A van Alen ${ }^{1}$, Bas E Dutilh ${ }^{2}$, Jan WP Kuiper ${ }^{1,4}$, \\ Hanneke JAA van Zoggel1,5, Minh Bao Huynh ${ }^{1,5}$, Hans-Dieter Görtz ${ }^{3}$, \\ Martijn A Huynen ${ }^{2}$ and Johannes HP Hackstein*1
}

\begin{abstract}
Address: ${ }^{1}$ Department of Evolutionary Microbiology, IWWR, Radboud University Nijmegen, Heyendaalseweg 135, 6525AJ Nijmegen, The Netherlands, ${ }^{2}$ Center for Molecular and Biomolecular Informatics, Nijmegen Center for Molecular Life Sciences, Radboud University Nijmegen Medical Centre, Geert Grooteplein 28, 6525GA Nijmegen, The Netherlands, ${ }^{3}$ Department of Zoology, Biological Institute, University of Stuttgart, Pfaffenwaldring 57, D-70569 Stuttgart, Germany, ${ }^{4}$ CIHR Group in Matrix Dynamics, University of Toronto, 150 College Street, Toronto, Ontario, Canada M5S 3E2 and ${ }^{5}$ Laboratoire de Recherche sur la Croissance Cellulaire, la Réparation et la Régénération Tissulaires (CRRET), EAC 7149 CNRS, Université Paris EST, 61, Avenue du Général de Gaulle, 94010 Créteil Cedex, France

Email: Rob M de Graaf - exorest@science.ru.nl; Theo A van Alen - T.vanAlen@science.ru.nl; Bas E Dutilh - dutilh@cmbi.ru.nl; Jan WP Kuiper - J.Kuiper@science.ru.nl; Hanneke JAA van Zoggel - zoggel@univ-paris12.fr; Minh Bao Huynh - mb.huynh@univ-paris12.fr; Hans-Dieter Görtz - Goertz@bio.Uni-Stuttgart.de; Martijn A Huynen - huynen@cmbi.ru.nl; Johannes HP Hackstein* - j.hackstein@science.ru.nl * Corresponding author
\end{abstract}

Published: 6 November 2009

BMC Genomics 2009, 10:514 doi:10.1186/147|-2164-10-514
Received: 14 May 2009

Accepted: 6 November 2009

This article is available from: http://www.biomedcentral.com/I47I-2/64/I0/5I4

(C) 2009 de Graaf et al; licensee BioMed Central Ltd.

This is an Open Access article distributed under the terms of the Creative Commons Attribution License (http://creativecommons.org/licenses/by/2.0), which permits unrestricted use, distribution, and reproduction in any medium, provided the original work is properly cited.

\begin{abstract}
Background: There are thousands of very diverse ciliate species from which only a handful mitochondrial genomes have been studied so far. These genomes are rather similar because the ciliates analysed (Tetrahymena spp. and Paramecium aurelia) are closely related. Here we study the mitochondrial genomes of the hypotrichous ciliates Euplotes minuta and Euplotes crassus. These ciliates are only distantly related to Tetrahymena spp. and Paramecium aurelia, but more closely related to Nyctotherus ovalis, which possesses a hydrogenosomal (mitochondrial) genome.

Results: The linear mitochondrial genomes of the hypotrichous ciliates Euplotes minuta and Euplotes crassus were sequenced and compared with the mitochondrial genomes of several Tetrahymena species, Paramecium aurelia and the partially sequenced mitochondrial genome of the anaerobic ciliate Nyctotherus ovalis. This study reports new features such as long 5 'gene extensions of several mitochondrial genes, extremely long cox 1 and cox 2 open reading frames and a large repeat in the middle of the linear mitochondrial genome. The repeat separates the open reading frames into two blocks, each having a single direction of transcription, from the repeat towards the ends of the chromosome. Although the Euplotes mitochondrial gene content is almost identical to that of Paramecium and Tetrahymena, the order of the genes is completely different. In contrast, the 33273 bp (excluding the repeat region) piece of the mitochondrial genome that has been sequenced in both Euplotes species exhibits no difference in gene order. Unexpectedly, many of the mitochondrial genes of $E$. minuta encoding ribosomal proteins possess $\mathrm{N}$-terminal extensions that are similar to mitochondrial targeting signals.
\end{abstract}

Conclusion: The mitochondrial genomes of the hypotrichous ciliates Euplotes minuta and Euplotes crassus are rather different from the previously studied genomes. Many genes are extended in size compared to mitochondrial genes from other sources. 


\section{Background}

Ciliates, unicellular eukaryotes, are extremely species-rich and colonize a very broad spectrum of ecological niches. They are characterized by complexes of cilia, used for swimming and food capturing and by a nuclear dimorphism that is unique for ciliates. All members possess a micronuclear genome, which is active in sexual reproduction, and a macronuclear genome that is transcriptionally active during somatic development and maintenance. In addition to the macronuclear and micronuclear genomes, aerobic ciliates also possess a mitochondrial genome. Although there are thousands of different ciliate species, only six mitochondrial genomes have been completely sequenced and analyzed thus far: $P$. aurelia $[1]$ and five Tetrahymena species: T. pyriformis, T. thermophila, T. pigmentosa, T. paravorax and T. malaccensis [2-4]. Only minor differences between the mitochondrial genomes of the Tetrahymena species were found. The mitochondrial genomes of $P$. aurelia and Tetrahymena species are also very similar; only two large blocks of genes are shifted between them but within these blocks the gene order is conserved. A third smaller block, containing the split mitochondrial ribosomal $\mathrm{rnl}$ gene, is duplicated in Tetrahymena but not in Paramecium. Although most of the sequenced mitochondrial genomes are circular mapping, the mitochondrial genomes of Paramecium and Tetrahymena are monomeric linear and capped with telomeres. No mitochondrial genomes have been sequenced in the order of hypotrichous ciliates that contain intensively studied species such as Oxytricha and Stylonichia as well as Euplotes, a genus widely distributed in freshwater and seawater environments. The two Euplotes species studied here (E. crassus and E. minuta) are both marine ciliates that were collected in the Mediterranean sea.

We investigated the mitochondrial genome organization of Euplotes for three reasons: firstly, because Euplotes is only distantly related to P. aurelia and the various Tetrahymena species, the only species from which mitochondrial genomes have been studied so far (Figure 1). Secondly, because Euplotes contains two morphologically different types of mitochondria, which might possess different genomes [5,6] and thirdly, because we assumed that Euplotes is more closely related to Nyctotherus ovalis than Tetrahymena or Paramecium. Phylogenetic analysis, however, did not support this assumption because of lacking statistical support (Figure 1). Nevertheless, it is likely that its organellar genome is closely related to the hydrogenosomal genome of Nyctotherus ovalis, which exhibits characteristics of a ciliate mitochondrial genome and significant sequence similarity to certain Euplotes genes. Nyctotherus ovalis, which thrives in the hindgut of various cockroach species, has been investigated extensively, but only $14 \mathrm{~kb}$ of its hydrogenosomal genome have been sequenced so far [7-10]. Here, we show that the mitochondrial genomes of E. crassus and E. minuta are linear with a large repeat region in the middle that is potentially involved in transcription initiation. The gene content of the Euplotes genome is almost identical to that of Paramecium and Tetrahymena, but the order of the genes is completely different. We discuss the observation that Euplotes contains extremely large cox genes and several other mitochondrial genes with large extensions. It is shown that several N-terminal extensions of the mitochondrial genes have the potential to function as mitochondrial import signals.

\section{Results and Discussion}

\section{Structure of the mitochondrial genomes}

The linear mitochondrial DNA of E. minuta has been completely sequenced with exclusion of the telomeres and a repeat region of more then 1000 base pairs that is located almost in the middle of the mitochondrial genome. The length of the sequenced mitochondrial genome of $E$. minuta clearly exceeds 41600 bp, while 33273 bp (excluding the repeat region) of the mitochondrial genome of $E$. crassus have been sequenced (Figure 2). The length of the telomeres can only be estimated roughly since it is known from investigation of 5 different Tetrahymena species that the composition and length of mitochondrial telomeres can differ enormously $[11,12]$. Also, in three Tetrahymena species the terminal repeats at both ends of the mitochondrial DNA are completely different. Moreover, analysis of the mitochondrial genome of T. malaccensis has shown that telomeric lengths can vary between 700 and $4200 \mathrm{bp}$ with an average size of $2600 \mathrm{bp}$. [12]. Since pulsed field gel electrophoresis of E. minuta DNA has indicated that the total length of the mitochondrial genome is clearly less than $48 \mathrm{~Kb}$ (Figure 3), it is likely that we have sequenced the total mitochondrial genome with exception of the telomeres. This interpretation is supported by the observation that chromosome walking using organelle DNA failed to provide evidence for the presence of additional DNA at the ends of the sequenced mitochondrial genome.

The central repeat region is made up from 18-bp units that are palindromic except for the positions 3-4/15-16. The repeat units are identical in E. crassus and E. minuta (Figure 4).

Because the direction of transcription of all mitochondrion encoded genes is away from this repeat region (Figure 2), we tested whether the palindrome exhibits significant sequence similarity to any known transcription factor binding site using the online motif comparison tool Tomtom [13]. As expected, no significant levels of sequence similarity were found (E-values $>0.1$ ). Notably, it has been observed that unrelated A-T rich repeat units serve as autonomously replicating sequences in the mitochondrial DNA of Paramecium and Tetrahymena; these 


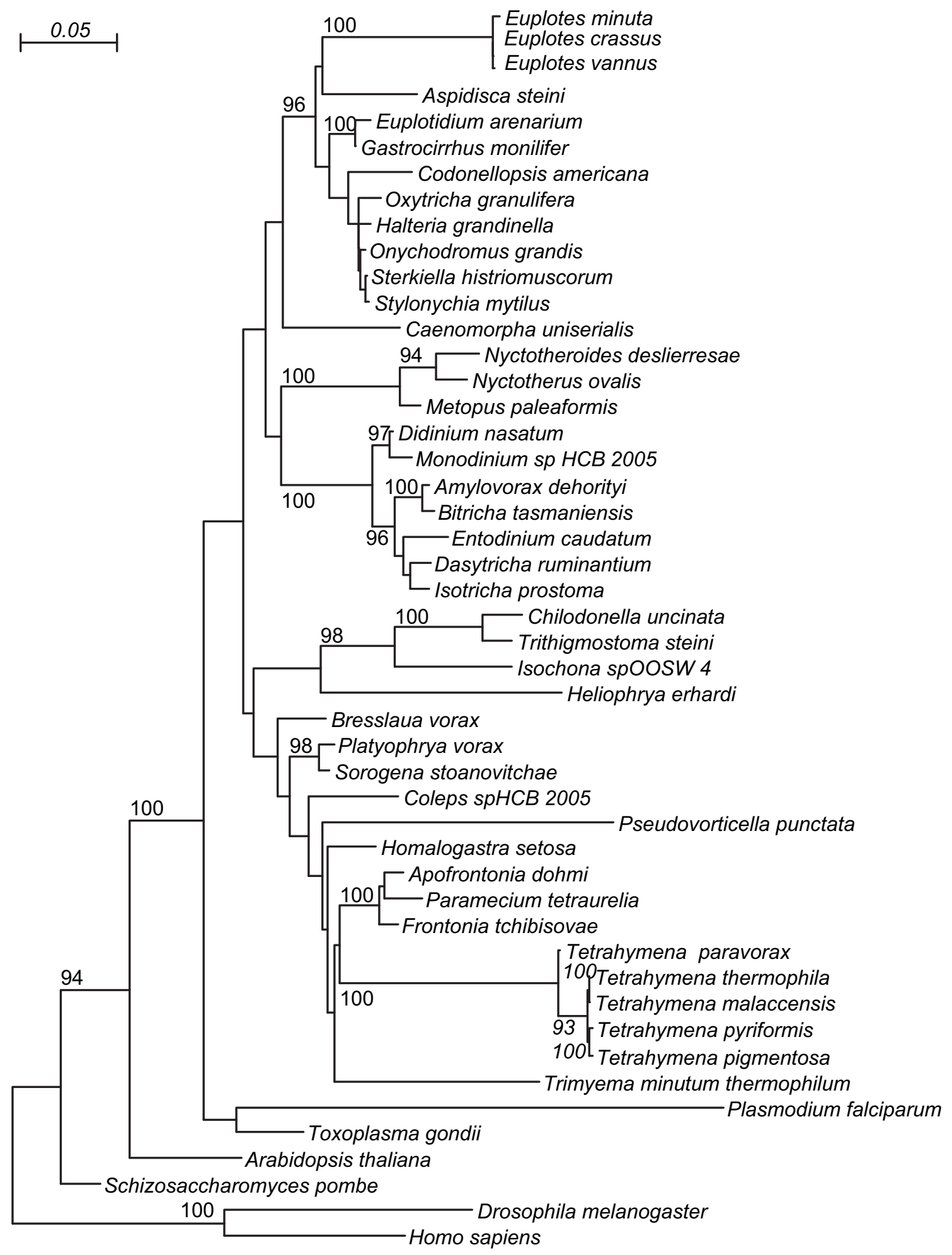

Figure I

Taxonomy of ciliates. A maximum likelihood phylogeny from selected I8S rRNA genes. Only bootstrap values equal or larger than $90 / 100$ are indicated. 


Euplotes minuta
mitochondrial genome
$\approx 42 \mathrm{~Kb}$

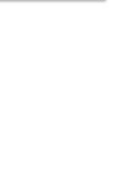

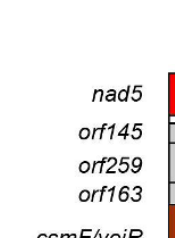

ccmF/yejR

$$
\text { M }
$$$$
c o b
$$

or78

$r n l$

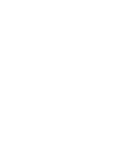

$\cos 2$

i

Euplotes crassus
mitochondrial genome
$($ partial $) \approx 35 \mathrm{~Kb}$

nad5

orf 449

orf197 ccmF/yejR

$c o b$

$M \multimap$ orf129

$r n l$

$\operatorname{cox} 1$

$\operatorname{nad} 4 L$

orf268

orf187

rps3(ymf64 / orf234)
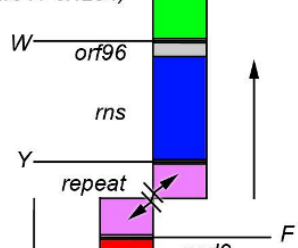

$\downarrow$

repeat

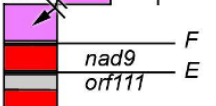

nad2

$r p / 16$

nad4

rps12

nad10

orf267

$r p / 2$

orf102

orf155

rps4

nad7

orf 49

nad1b

orf125 $Q$

orf380

atp9 9

orf170

$r p / 6$

nad1a

\section{Figure 2}

Mitochondrial gene map of Euplotes minuta and Euplotes crassus. Red: Complex I genes, blue: rRNA genes, green: ribosomal proteins, yellow: Complex III and IV genes, grey: unidentified open reading frames, pink: repeat region, dark grey: atp9 gene, white: intergenic spacers. Capital letters indicate the various tRNA genes. Arrows: direction of transcription. 


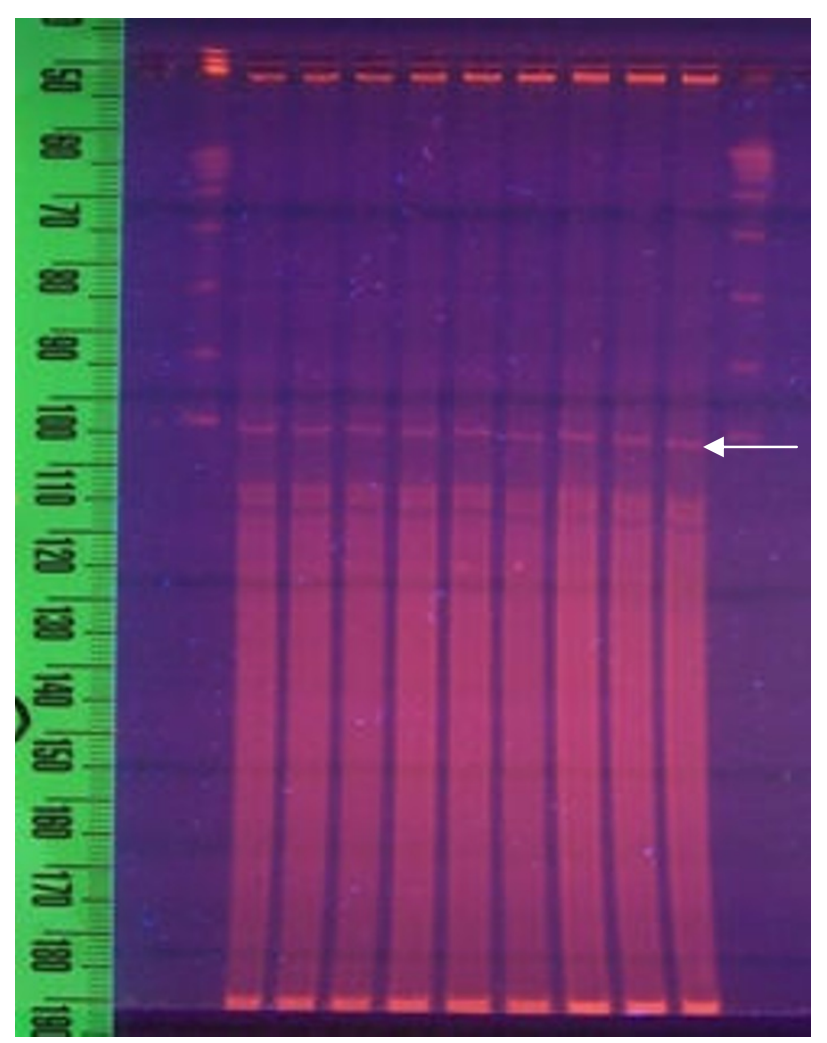

Figure 3

Pulsed field gel electrophoresis of genomic DNA of Euplotes minuta. Lanes I and I I contain lambda concatamer (marker). Lanes 2-I0 contain genomic DNA of Euplotes minuta. The mitochondrial band (arrow) is located just below the one lambda band ( $48 \mathrm{~Kb})$.

units are located at one end of the mitochondrial chromosome, close to the telomeric repeats [14-16]. Other examples of repeat regions in mitochondrial genomes of protists are found in the cryptophyte algae Rhodomonas salina [17] and Hemiselmis andersenii [18]. Both mitochondrial genomes contain a large complex repeat region that seems to play a role in transcription. However, the mito-

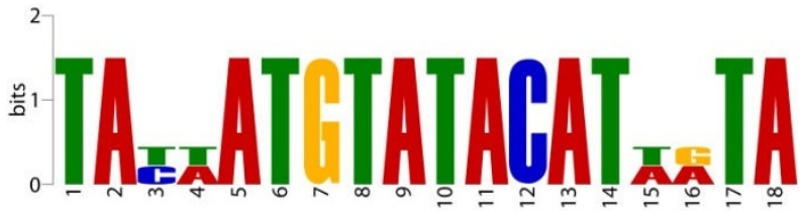

Figure 4

Structure of the central repeat unit. The repeat unit is palindromic except for the positions 3-4/15-16. It is identical in $E$. crassus and $E$. minuta. chondrial genomes of these unicellular cryptophyte algae are not linear but circular mapping.

The overall A+T content of the mitochondrial genome of E. minuta, (64.0\%), is much lower than in T. pyriformis $(78.7 \%)$ but significantly higher than in $P$. aurelia (59.0\%) [1]. Genes are tightly packed and the intergenic regions ( $4.1 \%$ of the genome) are generally short (ranging from 1 to 385 nucleotides, with an average size of 66 nucleotides). These intergenic regions have an overall $\mathrm{A}+\mathrm{T}$ content of $68.9 \%$ which is hardly higher than in the coding areas. We found eight cases where the orfs overlap (996 bp.) and no gene duplication. One gene (nad 1) was split into two parts that are located on different positions of the genome.

The overall A+T content of the sequenced part of the mitochondrial genome of E. crassus is $65.3 \%$. The genes in the mitochondrial genome of E. crassus are also tightly packed and intergenic spacers (4.2\%) have a length of 2 to 413 nucleotides with an average size of 77 nucleotides and an $\mathrm{A}+\mathrm{T}$ content of $68.4 \%$. Overlapping orfs were identified in 12 cases with overlaps varying in size from 3 to 100 base pairs.

\section{The mitochondrial genes of Euplotes minuta and Euplotes crassus}

The mitochondrial DNA of E. minuta includes 12 protein coding genes involved in the electron transport chain, 7 ribosomal protein coding genes, 2 ribosomal RNA genes, 7 transfer RNA genes, and one gene that encodes a cytochrome c assembly protein $(c c m F / j e y R)$ (Table 1$)$. Finally, 15 orfs were found with no detectable sequence similarity to known genes (Table 2). The sequenced part of the mitochondrial genome of E. crassus contains 10 genes of the electron transport chain, 6 ribosomal protein coding genes, 2 ribosomal RNA genes, 5 transfer RNA genes, the $c c m F / j e y R$ gene and 11 orfs with significant sequence similarity to E. minuta genes, but no detectable sequence similarity to other known genes (Table 1, 2).

There are no differences in gene order between the closely related E. crassus and E. minuta, but their gene order is completely different than that of the Tetrahymena species and $P$. aurelia (Figure 2). Only four genes could be found that have a conserved order in all these ciliate species: $r p l 2$ orf-nad10-rps12.

\section{Genes encoding components of the electron transport chain}

As shown in Table 1 all mitochondrion-encoded Complex I genes that were found in T. pyriformis and P. aurelia [4], were also found in E. minuta with the exception of nad6/ ymf62 that was identified as nad6 in T. pyriformis [3]. The mitochondrial genomes of all sequenced Tetrahymena spe- 
Table I: Mitochondrion-encoded genes of Euplotes minuta, Euplotes crassus and other ciliates

\begin{tabular}{|c|c|c|c|c|}
\hline gene & E. minuta & E. crassus & T. pyriformis & P. aurelia \\
\hline nadl & $*$ & ns & $*$ & $*$ \\
\hline nad2 & $*$ & $*$ & $*$ & $*$ \\
\hline nad3 & $*$ & ns & $*$ & $*$ \\
\hline nad4 & $*$ & $*$ & $*$ & $*$ \\
\hline nad4L & $*$ & $*$ & $*$ & $*$ \\
\hline nad5 & $*$ & $*$ & $*$ & $*$ \\
\hline nad6 & - & - & $*$ & $*$ \\
\hline nad7 & $*$ & $*$ & $*$ & * \\
\hline nad9 & $*$ & $*$ & $*$ & $*$ \\
\hline nadio & $*$ & $*$ & $*$ & $*$ \\
\hline rnI/lsu & $*$ & $*$ & $*$ & * \\
\hline rns/ssu & $*$ & $*$ & $*$ & $*$ \\
\hline$c o b$ & $*$ & $*$ & $*$ & * \\
\hline $\operatorname{cox} I$ & $*$ & $*$ & $*$ & * \\
\hline $\cos 2$ & $*$ & $*$ & $*$ & $*$ \\
\hline atp9 & $*$ & ns & $*$ & $*$ \\
\hline$c c m F / y e j R$ & $*$ & $*$ & $*$ & $*$ \\
\hline rps3 & $*$ & $*$ & $*$ & $*$ \\
\hline rps4 & $*$ & $*$ & - & - \\
\hline$r p s / 2$ & $*$ & $*$ & $*$ & $*$ \\
\hline rps/3 & - & - & $*$ & * \\
\hline rps I4 & - & - & $*$ & $*$ \\
\hline rps 19 & - & - & $*$ & - \\
\hline$r p / 2$ & $*$ & $*$ & $*$ & $*$ \\
\hline$r p 16$ & $*$ & ns & $*$ & - \\
\hline rpll4 & $*$ & $*$ & $*$ & $*$ \\
\hline rpllo & $*$ & $*$ & $*$ & $*$ \\
\hline $\operatorname{trnE}(G \mid u)$ & $*$ & $*$ & $*$ & - \\
\hline $\operatorname{trnF(Phe)}$ & $*$ & $*$ & $*$ & $*$ \\
\hline $\operatorname{trnH}(\mathrm{His})$ & $*$ & ns & $*$ & - \\
\hline $\operatorname{trnL}($ Leu) & - & - & $*$ & - \\
\hline $\operatorname{trn} M(M e t)$ & $*$ & $*$ & $*$ & $*$ \\
\hline $\operatorname{trnW}(\operatorname{Trp})$ & $*$ & $*$ & $*$ & $*$ \\
\hline $\operatorname{trn} Y(T y r)$ & $*$ & $*$ & $*$ & $*$ \\
\hline $\operatorname{trn} Q(G \ln )$ & $*$ & ns & - & - \\
\hline
\end{tabular}

*: gene present, -: gene absent. ns: not sequenced, these genes are expected to be located in the not sequenced part of the mitochondrial genome of Euplotes crassus

cies possess nad6/ymf62, which exhibits a significant sequence similarity with orf265 in P. aurelia.

In all Tetrahymena species and in P. aurelia the Complex I gene nad1 is split into a larger A and a smaller B part, which is located on the opposite strand. In E. minuta this gene is also split but located on the same strand. In E. crassus the corresponding part of the mitochondrial genome has not been sequenced (Figure 2).

The length of the nad2 gene of T. pyriformis, $P$. aurelia and N. ovalis (var. Bla. Ams) is almost the same but about 180 amino acids smaller than the nad2 gene of Bos taurus (cow). In contrast, the nad2 genes of both Euplotes species have large $\mathrm{N}$ terminal extensions. The nad2 gene of $E$. crassus has an extension of about 250 amino acids, and the homologous gene of E. minuta is around 500 amino acids longer. These extensions have no detectable sequence similarity to each other or to other known genes.

The Complex I gene nad $4 L$ has been identified by Brunk et al. in T. thermophila [3] (named ymf 58 in the other mitochondrial genomes of Tetrahymena species), in the hydrogenosomal genome of the anaerobic ciliate $N$. ovalis and in both Euplotes species (Table 1). It has not been annotated in Paramecium, but alignments of orf113 in $P$. aurelia with the Tetrahymena species and with the nad $4 L$ gene of $N$. ovalis shows that this orf113 is homologous to nad4L [10]. The nad7 genes of both Euplotes species are highly conserved; both have a small N-terminal extension (19 and 36 amino acids, respectively). These extensions are not similar to each other and are not found in other ciliates.

The only Complex III gene that is found in the mitochondrial genomes of the Tetrahymena species and $P$. aurelia is cytochrome-b $(c o b)$, which has also been identified in both Euplotes species (Table 1; Figure 2). The cob genes of both Euplotes species possess small N-terminal extensions that are not conserved while the remaining part of the gene is very well conserved. The Complex IV genes cytochrome oxidase 1 and 2 ( $\operatorname{cox} 1$ and $\operatorname{cox} 2$ ), are found in all Tetrahymena species, in P. aurelia and in both Euplotes species (Table 1; Figure 2). As shown earlier in $T$. pyriformis and $P$. aurelia both genes contain large (in frame) upstream open reading frames [4]. In Euplotes the cox2 frames reach extreme lengths, 1021 amino acids in E. crassus and 1017 amino acids in E. minuta (Figure 5a, b). The insert does not show significant similarity to any known gene, precluding the inference of function and functional constraints by sequence similarity. The sequencing of two Euplotes species, however, allows us to assess whether there is any selection on the protein coding sequence by calculating the ratio of non-synonymous over synonymous substitutions (dn/ds) and test for protein sequence conservation. Figure 6a shows the ClustalW alignment [19] between the Cox2 proteins in Euplotes and several other ciliate species. There are only two regions that could be unequivocally aligned among all the ciliates and of which the alignment did not depend on the program used [20,21]. These regions are indicated by the high conservation and quality bars in Figure 6 . They are also highly conserved between the two Euplotes sequences $(\mathrm{dn}=0)$, and overlap with the regions for which we detected likely sequence similarity with the PFAM Cox2 domain, albeit with an insignificant E-value for the $\mathrm{N}$-terminal part [22]. In contrast, there appear to be less constraints on the primary sequence of the 700 amino acid in-frame cox2 insert (65\% identity between the two Euplotes sequences). For $\operatorname{cox} 1$, we found a similar situation (see Additional file 1: Fig. S1 and Additional file 2:Fig. S2) When the Cox1 protein sequences of 
Table 2: Open reading frames (orfs) from Euplotes minuta that share sequence similarity with orfs from Euplotes crassus, Tetrahymena spp. and Paramecium aurelia.

\begin{tabular}{|c|c|c|c|}
\hline Euplotes minuta & Euplotes crassus & Tetrahymena spp. & Paramecium aurelia \\
\hline orf 96 & orflol & - & - \\
\hline orf-rps3 & orf-rps3 & ymf64 & orf234 \\
\hline orfl 87 & orfl 34 & - & - \\
\hline orf268 & orf3II & - & - \\
\hline orf78 & orfl 29 & - & - \\
\hline ccmF(partial) & orf 197 & - & - \\
\hline orfl 63 & orf449(partial) & - & - \\
\hline orf259 & orf449(partial) & - & - \\
\hline orfl 45 & orf449(partial) & - & - \\
\hline orfl II & orfi 75 & - & - \\
\hline nad2(partial) & orfl 47 & - & - \\
\hline- & orf45 & - & - \\
\hline orf267 & orf297 & orfl61/ymf74 & orfl 78-2/ymf84 \\
\hline orf 102 & - & - & - \\
\hline orfl 55 & orfl 56 & - & - \\
\hline rps4(partial) & orfl 41 & - & - \\
\hline orf 49 & ns & - & - \\
\hline orfl 25 & ns & - & - \\
\hline orf380 & ns & - & - \\
\hline orfl 90 & ns & - & - \\
\hline orfl 70 & ns & - & - \\
\hline
\end{tabular}

Partial: only a part of this gene/orf has significant sequence similarity. ns: these orfs are located in the part of the Euplotes crassus mitochondrial genome that has not been sequenced. -: no gene/orf found in this organism with significant sequence similarity. The remaining orfs in Tetrahymena spp. or Paramecium aurelia do not show significant sequence similarity (not shown).

both Euplotes species are compared with the Cox1 protein sequence of Bos taurus a large insert in frame of 380 amino acids was identified between positions 119-120. T. pyriformis and $P$. aurelia possess an insert of 271 amino acids in exactly the same position. Furthermore, it seems that the cox 1 genes of T. pyriformis and both Euplotes species contain N-terminal extensions of about 40 amino acids. The N-terminal extension in $P$. aurelia is a bit longer, about 83 amino acids. The N-terminal extensions of the cox 1 gene in both Euplotes species and in P. aurelia harbour a potential mitochondrial import signal that has been identified by the program Mitoprot [23]. In a recent publication [24] it was observed that latent mitochondrial targeting signals are present on the mitochondrial genomes of Arabidopsis thaliana and Oryza sativa. It is possible that some of the N-terminal extensions we find in Euplotes spp. play a role as latent mitochondrial targeting signals. Alternatively, they could function as an internal localization signal, resulting from a bias in nucleotide alteration, or even hint at the possibility of back-transfer of genes from the nucleus to the organelle [25]. Furthermore, the cox1 gene of E. minuta possesses a C-terminal extension (267 amino acids) that has not been found in the other ciliates, including E. crassus.

Another cytochrome c related gene, $c c m F / y e j R$, is also found in both Euplotes species (Table 1). It is a cytochrome $c$ assembly protein that encodes the potential catalytic subunit of cytochrome c lyase. There is a large difference in the lengths of the $c c m F / y e j R$ genes between these ciliates. T. pyriformis (513 amino acids) and E. minuta (461 amino acids) have a large C-terminal extension. The corresponding extensions in $P$. aurelia (256 amino acids) and E. crassus (243 amino acids) are significantly smaller.

Only one Complex V gene, ATPase 9, has been identified in E. minuta. It is also located on the mitochondrial genomes of $T$. pyriformis and $P$. aurelia (Table 1 ). The corresponding region in $E$. crassus was not sequenced.

\section{Ribosomal proteins}

Mitochondrial genes encoding mitochondrial ribosomal proteins are common in plants and protists but have never been found in the mitochondrial genomes of animals. Ciliates possess a limited number of ribosomal proteins on their mitochondrial genomes. So far 7 ribosomal proteins have been identified in E. minuta (Table 1). Another ribosomal protein, rpl14 from E. crassus, which is present in all other ciliate mitochondrial genomes, has an N-terminal extension (33 amino acid) that has no significant similarity with other known proteins. Similar extensions were observed for the rpl16, rps4 and rps12 genes in both ciliates E. crassus and E. minuta (Table 3 ). When the mitochondrial genes were examined with the mitochondrial import signal prediction program Mitoprot [23] we found high scoring hits for all ribosomal proteins in $E$. 

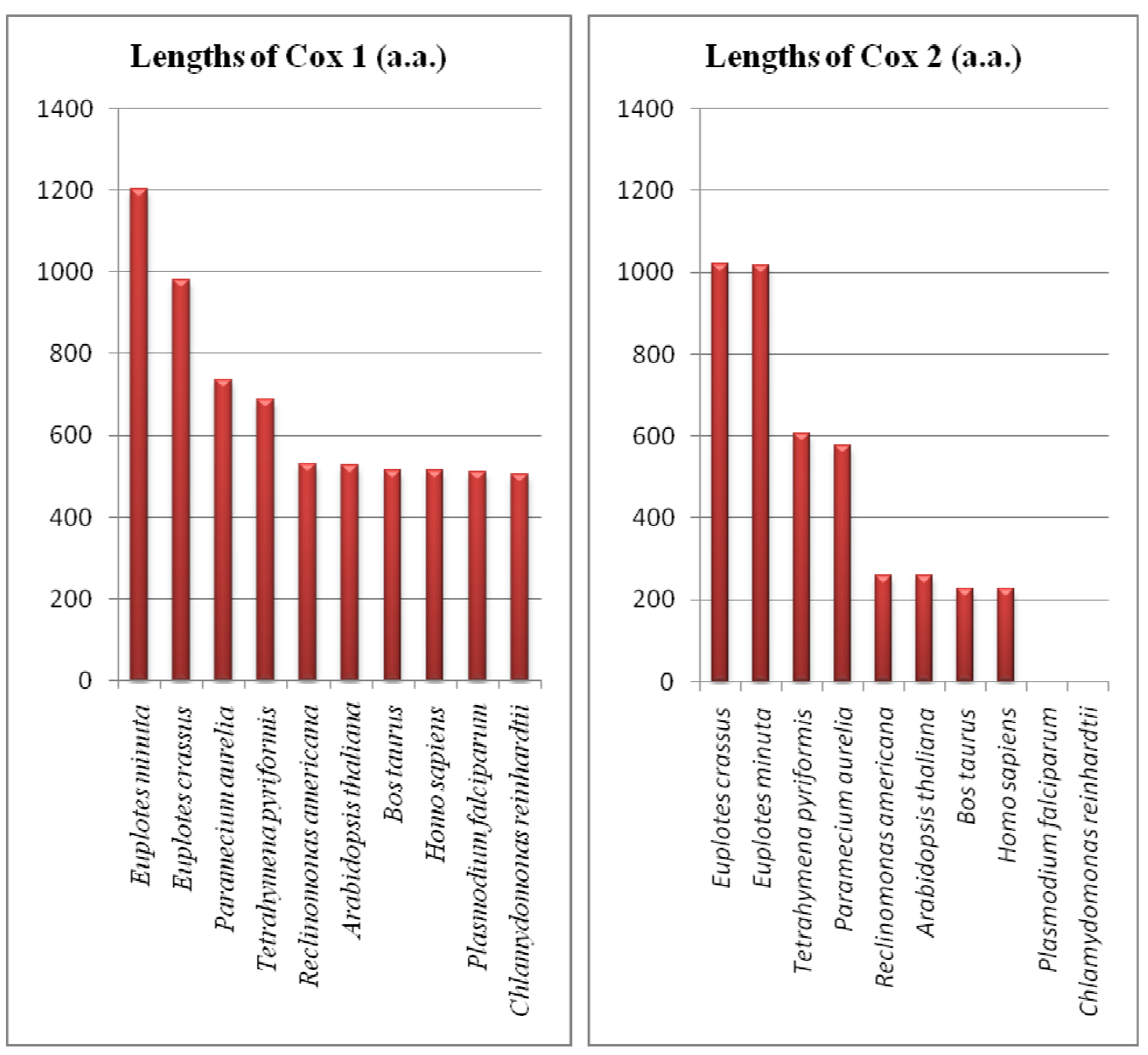

\section{Figure 5}

Length of coxI and cox2 open reading frames (in amino acids) from E. crassus and E. minuta compared to other organisms.

minuta and all ribosomal proteins in E. crassus except one. All these ribosomal proteins also contained a predicted cleavage site. Analyses of the mitochondrial ribosomal proteins of $T$. pyriformis and $P$. aurelia indicated that also some of these proteins possessed a potential import signal. An analysis based on the signal prediction programs Predotar [26] and TargetP [27] gave less hits but still identified a significant number of potential mitochondrial import signals (Table 3).

\section{tRNA genes}

Among eukaryotes the number of mitochondrial-encoded tRNA genes varies from 26 tRNAs in Reclinomonas americana to zero in apicomplexa [28]. Seven different tRNA genes were identified in the mitochondrial genome of $E$. minuta (trnE, trnF, trnH, trnM, trnY, trnQ and trnW) in contrast to only four such tRNA genes in P. aurelia (trnF, trnM, trnW and trnY) (Table 1) [1]. In E. crassus only 5
tRNA genes were identified. Also, in T. pyriformis a set of seven tRNA genes were identified i.e. $\operatorname{trn} E, \operatorname{trn} F, \operatorname{trn} H, \operatorname{trnL}$, trnM, trnW and trnY [4]. The mitochondrial-encoded tRNA for Glutamine (trnQ) seems to be unique for Euplotes, since it was not identified in either T. pyriformis or in P. aurelia; trnL is duplicated in T. pyriformis. Two different programs (tRNAscan-SE and ARAGORN) did not detect a tRNA for tryptophan (W); instead, this tRNA was identified as a tRNA for selenocystein. Recently however, the presence of trnW in the mitochondrial genome of $E$. crassus was experimentally confirmed by Turanov et al. [29].

\section{Open reading frames}

Additional 17 orfs have been identified in E. minuta and 13 orfs in E. crassus (Table 2). One orf (rps3) of E. minuta and E. crassus has, after BlastX and BlastN searches, detectable sequence similarity with orfs from $T$. pyriformis and $P$. 


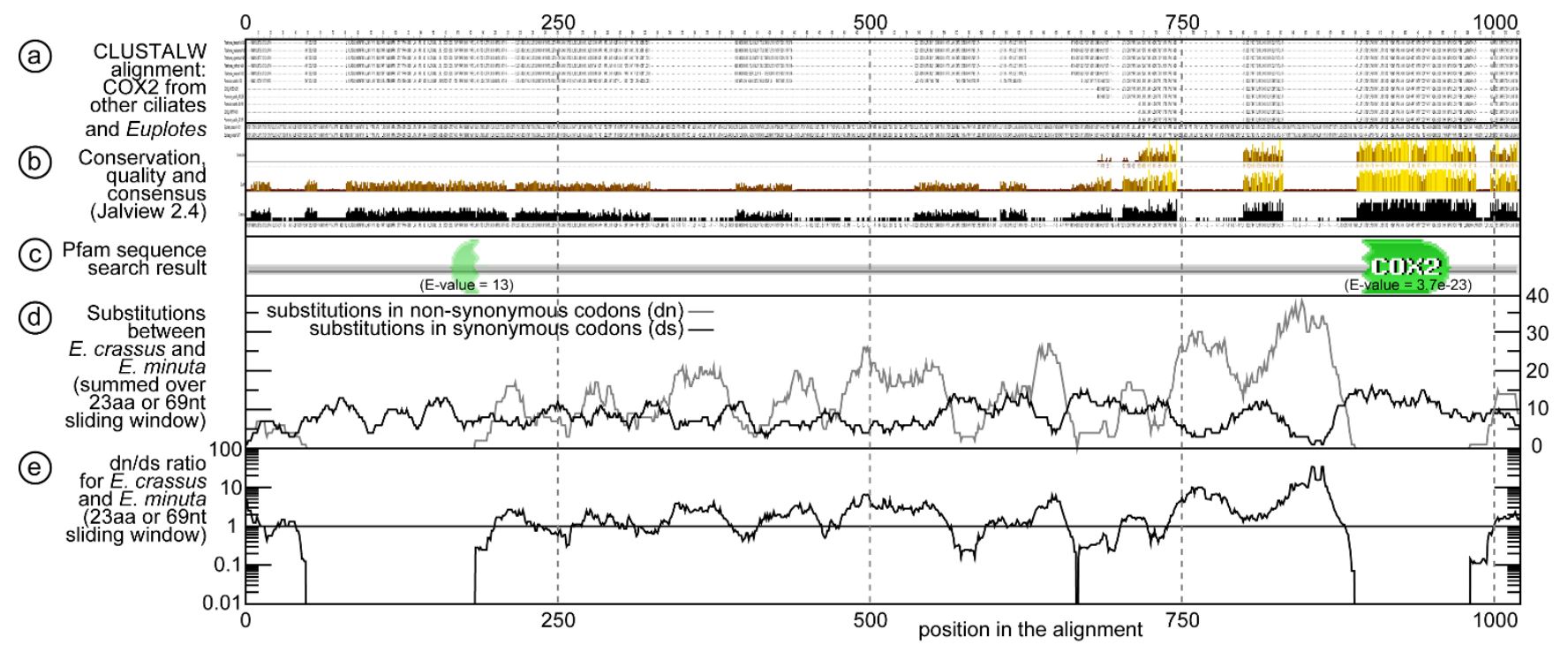

Figure 6

Alignment analysis of Euplotes cox2. a) ClustalW alignment of cox2 from other ciliates and Euplotes; b) conservation, quality and consensus scores of the multiple alignment in (a) according to Jalview; c) Pfam search result including an insignificant hit to the Cox2 Pfam domain in the $\mathrm{N}$-terminal conserved region of the gene; $d$ ) number of non-synonymous (ds) and synonymous (ds) base substitutions observed between $E$. minuta and $E$. crassus per 69 nt sliding window; e) dn/ds ratio based on (d).

aurelia (ymf64/orf234). In T. thermophila the gene ymf64 has been identified as a putative ribosomal protein, based on physicochemical parameters of the predicted protein [3]. Comparison of an alignment of the ymf64 homologs in the ciliates with the Hidden Markov Models (HMMs) in PFAM, using the sensitive profile-profile based homology detection tool HHsearch [30] indicates that $y m f 64$ exhibits significant sequence similarity with the C-terminal domain of the ribosomal protein S3 $(\mathrm{P}<2.1 \mathrm{E}-5$, Additional file 3: Fig. S3). An HMM of the genes that are currently annotated as rps3 in the Tetrahymena species and in $P$. aurelia indicated that they are homologous to the N-terminal domain of the ribosomal protein S3 $(\mathrm{P}<2.1 \mathrm{E}-5)$. The gene length of ymf64 in T. thermophila is 330 amino acids; in P. aurelia (orf234) it has a length of 234 amino acids. The orthologous Euplotes genes are much larger (767 and 768 amino acids, respectively). We could not detect significant sequence similarity of the S3 N-terminal domain to any of the Euplotes sequences.

For the remaining 16 orfs in E. minuta and 12 in E. crassus no homologous genes were found using BlastX and BlastN searches. However, one of these, orf267(orf 297 in E. crassus), which is part of the conserved region of four genes in Euplotes spp., is weakly conserved when compared to orf161/ymf74 in T. pyriformis and orf178-2/ymf84 in $P$. aurelia (Table 2)

\section{Mitochondrial ribosomal RNA genes}

The mitochondrial large and small subunit ribosomal RNA genes in five Tetrahymena species and in $P$. aurelia are split into two pieces [4]. In all these Tetrahymena species the $r n l$ gene is duplicated. Analysis of the mitochondrial genomes of E. minuta and E. crassus by BlastN identified the regions were the $r n l$ and $r n s$ genes are situated. The $r n l$ gene in Euplotes species is not duplicated as in the Tetrahymena species. Even by sensitive Smith-Waterman queries [31] with selected parts of the $r n l$ and $r n s$ sequences from other ciliate species, we did not find any indication that these genes were split in Euplotes (not shown). Both, the region containing the putative $r n l$ and the region containing the putative $r n s$, have significant sequence similarity to the $r n l$ and the $r n s$ of the published mitochondrial ciliate ribosomal RNAs. Nevertheless, the regions of significant sequence similarity do not cover the complete published ribosomal RNAs, prohibiting complete sequence alignment and therewith assessment as to whether these RNAs are complete or interrupted. As expected, a 5S rRNA gene could not be identified.

\section{Genetic code}

Analysis of the codon usage as described in the Methods section confirmed that both Euplotes species use the protozoan mitochondrial code, with TGA encoding tryptophan. There are a few spurious predictions (TCG, ATG and ACC in E. crassus and TAG, ATT, ATG and ACC in E. minuta), but for all these cases we find the correct translation at an almost equal score. The prediction that TAG 
Table 3: Importsignal and cleavage-site prediction by Mitoprot of mitochondrion encoded genes.

\begin{tabular}{|c|c|c|c|c|c|c|c|c|}
\hline gene & $\begin{array}{c}\text { Euplotes } \\
\text { minuta }\end{array}$ & $\begin{array}{l}\text { Euplotes } \\
\text { crassus }\end{array}$ & $\begin{array}{c}\text { Tetrahymena } \\
\text { Pyriformis }\end{array}$ & $\begin{array}{c}\text { Paramecium } \\
\text { aurelia }\end{array}$ & $\begin{array}{c}\text { Blastocystis } \\
\text { (DMP) }\end{array}$ & $\begin{array}{c}\text { Reclinomonas } \\
\text { americana }\end{array}$ & $\begin{array}{c}\text { Arabidopsis } \\
\text { thaliana }\end{array}$ & Oryza sativa \\
\hline nadla & $0.3731 Y$ & & $0.9380 \mathrm{Y}$ & $0.8786 Y$ & $0.0535 \mathrm{~N}$ & $0.204 \mathrm{IN}$ & $0.0304 \mathrm{~N}$ & $0.0318 Y$ \\
\hline nadlb & $0.0179 \mathrm{~N}$ & & $0.0155 \mathrm{~N}$ & $0.0835 \mathrm{~N}$ & & & & \\
\hline nad2 & $0.9057 Y * \#$ & $0.0229 Y$ & $0.1574 \mathrm{~N}$ & $0.9175 Y$ & $0.1689 \mathrm{~N}$ & $0.0435 \mathrm{~N}$ & $0.1369 \mathrm{~N}$ & $0.0497 \mathrm{~N}$ \\
\hline nad3 & $0.1585 \mathrm{~N}$ & & $0.0175 \mathrm{~N}$ & $0.1252 \mathrm{~N}$ & $0.1418 \mathrm{~N}$ & $0.0504 \mathrm{~N}$ & $0.0154 \mathrm{~N}$ & $0.0042 \mathrm{~N}$ \\
\hline nad4 & $0.0642 Y$ & $0.7605 \mathrm{~N}$ & $0.6499 \mathrm{~N}$ & $0.4964 \mathrm{~N}$ & $0.5047 Y$ & $0.7783 \mathrm{~N}$ & $0.1300 \mathrm{~N}$ & $0.0805 \mathrm{~N}$ \\
\hline $\operatorname{nad} 4 L$ & $0.0155 \mathrm{~N}$ & $0.0103 \mathrm{~N}$ & $0.0657 \mathrm{~N}$ & & $0.3538 \mathrm{~N}$ & $0.2082 Y$ & $0.3533 Y$ & $0.3009 \mathrm{~N}$ \\
\hline nad5 & $0.1896 \mathrm{~N}$ & $0.0983 \mathrm{N \#}$ & $0.3453 \mathrm{~N}$ & $0.7374 Y$ & $0.5069 \mathrm{~N}$ & $0.3453 Y$ & $0.1255 Y$ & $0.1675 Y$ \\
\hline nad6 & & & & & & $0.1870 \mathrm{~N}$ & $0.9123 Y$ & $0.7924 \mathrm{~N} \#$ \\
\hline nad7 & $0.1782 \mathrm{~N}$ & $0.1914 \mathrm{~N}$ & $0.2221 Y \#$ & $0.3188 \mathrm{~N}$ & $0.6599 Y^{*} \#$ & $0.677 \mathrm{IN}$ & $0.6916 \mathrm{N \#}$ & $0.4186 \mathrm{~N}$ \\
\hline nad8 & & & & & $0.3912 \mathrm{~N}$ & & & \\
\hline nad9 & 0.8492 Y\# & $0.960 I Y$ & $0.6518 \mathrm{~N}$ & $0.1990 \mathrm{~N}$ & $0.9159 Y^{*}$ & $0.2870 \mathrm{~N}$ & $0.0587 \mathrm{~N}$ & $0.1915 \mathrm{~N}$ \\
\hline nadlo & $0.3770 Y^{*}$ & $0.2760 Y$ & $0.1351 Y$ & $0.2149 Y$ & & $0.238 \mathrm{IN}$ & & \\
\hline nadII & & & & & $0.0456 \mathrm{~N}$ & $0.0214 \mathrm{~N}$ & & \\
\hline$c o b$ & $0.0081 \mathrm{~N}$ & $0.1385 \mathrm{~N}$ & $0.0323 \mathrm{~N}$ & $0.1088 \mathrm{~N}$ & & $0.6913 \mathrm{~N}$ & $0.2913 \mathrm{~N} * \#$ & $0.2609 \mathrm{~N} * \#$ \\
\hline $\operatorname{cox} I$ & $0.9306 \mathrm{~N}$ & $0.9803 \mathrm{~N}$ & $0.1062 \mathrm{~N}$ & $0.9618 N^{*}$ & & $0.0144 Y^{*}$ & $0.2360 \mathrm{~N}^{*}$ & $0.1908 \mathrm{~N}^{*}$ \\
\hline $\cos 2$ & $0.0503 \mathrm{~N}$ & $0.0203 \mathrm{~N}$ & $0.4944 Y$ & $0.64 \mid 4 Y$ & & $0.0327 \mathrm{~N}$ & $0.0176 \mathrm{~N}$ & $0.3447 \mathrm{~N}$ \\
\hline $\operatorname{cox} 3$ & & & & & & $0.0600 Y$ & $0.0605 \mathrm{~N}$ & $0.0222 \mathrm{~N}$ \\
\hline atp I & & & & & & & $0.2910 \mathrm{~N}$ & $0.1920 \mathrm{~N}$ \\
\hline atp6 & & & & & & & $0.2621 \mathrm{~N}$ & $0.0085 \mathrm{~N}$ \\
\hline $\operatorname{atp} 9$ & $0.7172 Y$ & & $0.3150 \mathrm{~N}$ & & & $0.1172 Y$ & $0.0397 \mathrm{~N}$ & $0.494 I Y$ \\
\hline yejR & $0.4823 \mathrm{~N}$ & $0.1926 \mathrm{~N} * \#$ & $0.1009 \mathrm{~N}$ & $0.9263 Y$ & & & & \\
\hline rpsl & & & & & & $0.6830 \mathrm{~N}$ & & $0.0249 \mathrm{~N}$ \\
\hline rps2 & & & & & & $0.0626 Y$ & & $0.547 I Y$ \\
\hline rps3 & $0.9987 Y \#$ & $1.000 Y * \#$ & $0.1184 \mathrm{~N}^{*}$ & $0.0581 \mathrm{~N}$ & $0.6604 \mathrm{~N}$ & $0.1605 Y$ & $0.56 I I N$ & $0.4670 \mathrm{~N}$ \\
\hline rps 4 & $0.9898 Y$ & $0.9364 Y^{*} \#$ & & & & $0.7786 \mathrm{~N}$ & $0.8602 Y^{*} \#$ & $0.9984 Y^{*} \#$ \\
\hline rps7 & & & & & & $0.1327 \mathrm{~N}$ & $0.1334 \mathrm{~N}$ & $0.2046 \mathrm{~N}$ \\
\hline rps8 & & & & & $0.6514 \mathrm{~N}$ & $0.5082 \mathrm{~N}$ & & \\
\hline rpslo & & & & & $0.8777 \mathrm{~N}$ & $0.1099 \mathrm{~N}$ & & \\
\hline rpsll & & & & & & $0.0295 \mathrm{~N}$ & & \\
\hline rps 12 & $0.9998 Y * \#$ & 0.9999Y*\# & $0.935 \mid Y^{*}$ & $0.9683 Y$ & $0.9975 Y^{*}$ & $0.3302 \mathrm{~N}$ & $0.2447 \mathrm{~N}$ & $0.1545 \mathrm{~N}$ \\
\hline$r p s / 3$ & & & $0.1107 \mathrm{~N}$ & $0.6322 \mathrm{~N}$ & $0.9347 N^{*}$ & $0.7738 \mathrm{~N}^{*}$ & & $0.3213 Y$ \\
\hline rps 14 & & & $0.9868 Y *$ & $0.0604 \mathrm{~N}$ & $0.1811 \mathrm{~N}$ & $0.0376 N^{*}$ & & \\
\hline rps 19 & & & $0.9934 N^{*}$ & & $0.1278 \mathrm{~N}$ & $0.88 \mathrm{I} 2 Y^{*}$ & & $0.7065 N^{*} \#$ \\
\hline rpll & & & & & & $0.0921 \mathrm{~N}$ & & \\
\hline$r p / 2$ & $0.9997 Y$ & $0.9982 Y$ & $0.9975 Y *$ & $0.9854 Y \#$ & $0.4959 N^{*}$ & $0.4860 Y^{*}$ & $0.9974 Y^{* \#}$ & $0.9972 Y^{*} \#$ \\
\hline$r p 15$ & & & & & & $0.5942 \mathrm{~N}$ & $0.0114 \mathrm{~N}$ & $0.0437 \mathrm{~N}$ \\
\hline rpl6 & & & $0.5948 \mathrm{~N}$ & & $0.685 \mathrm{IN}^{*}$ & $0.3297 \mathrm{~N}$ & & \\
\hline rpllo & & & & & & $0.8245 \mathrm{~N}$ & & \\
\hline rpll I & & & & & $0.9694 N$ & $0.0835 \mathrm{~N}$ & & \\
\hline$r p l / 4$ & $0.9298 Y * \#$ & $0.0484 \mathrm{~N}$ & $0.2054 \mathrm{~N}$ & $0.0817 \mathrm{~N}$ & $0.4278 Y$ & $0.1262 \mathrm{~N}$ & & \\
\hline$r p / 16$ & $0.9982 Y * \#$ & $0.9655 Y * \#$ & $0.9947 Y * \#$ & $0.8770 \mathrm{~N}$ & $0.7748 Y^{*} \#$ & $0.4554 Y$ & $0.9809 Y^{*}$ & $0.7261 Y^{*}$ \\
\hline$r p / / 8$ & & & & & & $0.5305 \mathrm{~N}^{*}$ & & \\
\hline rplla & & & & & & $0.6495 Y \#$ & & \\
\hline rpl20 & & & & & & 0.9939Y\# & & \\
\hline$r p / 27$ & & & & & & $0.6704 Y$ & & \\
\hline$r p / 3 I$ & & & & & & $0.6276 \mathrm{~N}$ & & \\
\hline$r p / 32$ & & & & & & $0.9946 \mathrm{~N} * \#$ & & \\
\hline rpl34 & & & & & & $0.9508 Y^{*}$ & & \\
\hline
\end{tabular}

Bold face: significant import probability due to Mitoprot prediction. italics: genes used by Ueda et al. [24]. Y: cleavage site predicted with Mitoprot. $\mathrm{N}$ : no cleavage site predicted with Mitoprot. Putative $\mathrm{N}$-terminal targeting sequences for ribosomal proteins were also calculated using the programs Predotar [26] and TargetP [27] *: these proteins could be imported into mitochondria according to Predotar. \#: these proteins could be imported into mitochondria according to TargetP.

would code for a serine in E. minuta is only based on a single aligned occurrence of the codon, caused possibly by a sequence error or a misalignment (not shown).

\section{Conclusion}

When the mitochondrial genome of T. pyriformis was published and compared with that of $P$. aurelia, it seemed that 
the mitochondrial gene order in ciliates was very well conserved [4]. With the determination of the mitochondrial genome of a third ciliate genus, belonging to a completely different taxon, we have shown that the gene order in mitochondrial genomes of ciliates can be very different while a similar set of genes is conserved. Also the linearity of the mitochondrial chromosomes is conserved. This might suggest that monomeric linear mitochondrial chromosomes, which are relatively rare among protozoa and animals [32], are characteristic for ciliates. This possibility is corroborated by the observation that also species belonging to the sister taxon apicomplexa possess linear mitochondrial chromosomes [33]. However, it should be noted that among yeasts even the mitochondrial genomes of closely related species differ with respect to their linearity/circularity [32].

From the 17 unidentified open reading frames in the mitochondrial genome of Euplotes minuta two could be found with significant sequence similarity to $T$. pyriformis and $P$. aurelia (Table 2). This contrasts with the situation in T. pyriformis and P. aurelia where 13 out of the 22 unidentified open reading frames in T. pyriformis were also found in P. aurelia [4]. One of these orfs, $y m f 64$, has now, with the aid of the Euplotes sequences and profile based homology searches been shown to be significantly similar to a known protein domain, the C-terminal part of the Rps3 protein. This suggests that with the sequencing of more mitochondrial genomes of the ciliates also for other orfs sequence similarity might be detected with known mitochondrial genes.

One of the rare mitochondrial features present in the mitochondrial genomes of $T$. pyriformis and P. aurelia is a split nad1 gene. This split gene has also been identified in Euplotes and thus seems to be specific for a large group of (maybe all) ciliates.

One of the most striking differences between the mitochondrial genomes of Euplotes and those of Tetrahymena species and $P$. aurelia is the presence of a large repeat region in the middle of the mitochondrial genome of both Euplotes species that seems to be used as a bi-directional transcription start. No such repeat was found in Tetrahymena species and P. aurelia and, in contrast to Euplotes, the transcription direction changes several times.

Another striking feature of the genes in the mitochondrial genome of Euplotes species is the presence of very large open reading frames. Most of these large orfs contain $\mathrm{N}$ terminal extensions, but in some cases, like the cox 1 and cox2 genes, large inserts in frame cause this effect. Such inserts in frame were also detected in Tetrahymena sp. and $P$. aurelia. Surprisingly, all of the N-terminal extensions of genes encoding ribosomal proteins of Euplotes minuta con- tain a potential targeting signal for import into mitochondria. This is the first report identifying such import signals in mitochondrial-encoded genes in organisms other than plants.

Sequencing and analyzing the mitochondrial genomes of E. crassus and E. minuta shows that the mitochondrial genomes of ciliates are rearranged more extensively than previously thought. Sequencing of the mitochondrial genome of E. minuta also did not provide any evidence for the presence of a slightly deviating, alternative genome that might be expected for the two morphs of mitochondria observed in this species. Studying these mitochondrial genomes has provided additional information about the evolution of mitochondria in general and in particular about the evolution of the elusive hydrogenosomal genome of Nyctotherus ovalis [10], which appeared to be more related to the mitochondrial genome of Euplotes than to those of Paramecium and Tetrahymena.

\section{Methods}

E. minuta cells were collected in 2005 in the Mediterranean sea near Stareso, Corsica, France (Em. S1, E. minuta Stareso1), cultured in the laboratory in artificial sea water obtained from the Botanical and Zoological Garden Stuttgart (Wilhelma) and fed with Klebsiella minuta grown on nutrient agar. For the isolation of DNA, a concentrated sample of living cells was mixed with $8 \mathrm{M}$ guanidiniumchloride. A 10:1 mixture with $1 \mathrm{M}$ phosphate buffer $\mathrm{pH}$ 7.0 was made, adsorbed on a hydroxyapatite (Biorad, biogel HTP) column $(1 \mathrm{~cm} \times 0.4 \mathrm{~cm})$ and washed with $4 \mathrm{M}$ guanidiniumchloride, $100 \mathrm{mM}$ phosphate buffer $\mathrm{pH}=$ 7.0, followed by washing with $4 \mathrm{M}$ guanidiniumchloride, $200 \mathrm{mM}$ phosphate buffer $\mathrm{pH}=7.0$. Subsequently, the bulk of DNA was eluted with $4 \mathrm{M}$ guanidiniumchloride $500 \mathrm{mM}$ phosphate buffer $\mathrm{pH}=7.0$. The DNA was diluted with 1 volume water and precipitated with $10 \mathrm{v} / \mathrm{v} \% 3 \mathrm{M}$ sodiumactetate $\mathrm{pH}=5.2$ and $50 \mathrm{v} / \mathrm{v} \%$ propanol-2 for 10 minutes at room temperature. After precipitation and washing the pellet was air dried. Finally, the DNA pellet was dissolved in DEPC treated water (Invitrogen).

The dissolved DNA was loaded on a pulsed field agarose gel ( $1 \%$ agarose type II medium EEO, Sigma) and run at $170 \mathrm{~V}(145 \mathrm{~mA})$ ramping from $2.5 \mathrm{~s}-25 \mathrm{~s}$ for 16 hours PFGE with a LKB 2015 Pulsaphor plus control unit.

The band just below the first band of the lambda marker (Figure 3) was cut out and the DNA extracted. The position of the mitochondrial band on pulsed field gel is a clear indication of a linear mitochondrial genome. Circular mitochondrial genomes of this size should run much faster in the gel. The DNA of the band was digested with Sau 3A and then size fractionated on an agarose gel. The DNA from these fractions was isolated from the gel, 
ligated in pUC-18 digested with BamH1 and transformed in E. coli DH101B cells. The titre of the library was $1.12 \times$ $10^{5}$. From this library, plasmid DNA from 288 different colonies was sequenced with an ABI prism 3730 online capillary sequencing machine and the mitochondrial genome was assembled as described below. The gene library was constructed by Genterprise, Mainz, Germany.

E. crassus was collected from shallow coastal waters of the sandy beach of Porto Recanati $\left(43^{\circ} 26^{\prime} \mathrm{N}, 13^{\circ} 40^{\prime} \mathrm{E}\right)$ on the Italian Adriatic Coast, $50 \mathrm{~km}$ south of Ancona, July 1984 and cultured in the laboratory in artificial sea water ( $\mathrm{NaCl} 465 \mathrm{mM}, \mathrm{KCl} 10 \mathrm{mM}, \mathrm{MgCl}_{2} \cdot 6 \mathrm{H}_{2} \mathrm{O} 24.8 \mathrm{mM}$, $\mathrm{MgSO}_{4} \cdot 7 \mathrm{H}_{2} \mathrm{O} 28.1 \mathrm{mM}, \mathrm{CaCl}_{2} 10.4 \mathrm{mM}, \mathrm{NaHCO}_{3} 2.4$ $\mathrm{mM}$ pH 8.0).

Initially, a culture was kept in artificial seawater in an Erlenmeyer flask and fed with a small piece of raw beef. Alternatively, a set of $200 \mathrm{ml}$ tissue flasks was first siliconized, filled with approximately $50 \mathrm{ml}$ of artificial seawater, and inoculated with $E$. crassus cells. These cultures were fed with HB101 E. coli cells.

Total DNA of E. crassus was isolated by dissolving cells in $8 \mathrm{M}$ guanidiniumchloride and purification by hydroxyapatite as described above for E. minuta.Four fragments of different mitochondrial genes were obtained by PCR with degenerated primers on this DNA, i.e. primers directed against the ribosomal genes $\mathrm{rnl}$ (5'-GTCAAGAGAGAAACAGC-3', 5'-GCATAGGGTCTTCCCGTC-3'), rns (5'TGTGCCAGCAGCCGCGGTAA-3', 5'-TCCCMTACCRGTACCTTGTGT-3') and the complex I genes nad7 (5'TTCGGWCCHCARCAYCCHGC-3', 5' -CTRTCRACYTCWCCRAARAC-3') and nad10 (5'-TTYGGHYTNGCHTGHTG-3', 5'ARDGCYTCDSWDGTDGGDGGDCA-3') On these gene fragments primers for long range PCR were developed and long range PCR with LA-Taq-polymerase $(5 \mathrm{U} / \mu \mathrm{l})$ (Takara bio inc.) was performed. The long range PCR products were digested with different restriction enzymes, subcloned in pUC-18 (Sigma) or in pGEM-T easy (Promega) and sequenced. Sequencing was performed at the DNA diagnostics centre of the Nijmegen University Medical Center using M13 forward and reverse primers.

All sequences have been submitted to NCBI GenBank. The GenBank accession-numbers are for E. minuta GQ903130 and for E. crassus GQ903131. The protein identifiers are displayed in additional file 4 .

\section{Analysis of the sequence data}

Sequences were edited using chromas Lite 2.01 http:// www.technelysium.com.au The edited sequences were assembled using BioEdit version 7.0.9.0 [34]. Open reading frames were identified with orf Finder http:// www.ncbi.nlm.nih.gov/gorf/gorf.html. tRNAs were identified with tRNAscan-SE http://lowelab.ucsc.edu/tRNAs can-SE/ and ARAGORN [35]. Sequence similarity searches of deduced amino acid sequences were performed with BLASTX and BLAST2 [36]. The nucleotide sequence similarity searches were conducted with BLASTN (NCBI) and FASTA (EMBL-EBI). Import signal prediction was done with Mitoprot [23], Predotar [26] and TargetP [27]. Alignments were made with ClustalX2 and ClustalW [37]. The program Nucleic Acid Dot Plots http:// www.vivo.colostate.edu/molkit/dnadot/index.html was used for identifying repeat structures.

The sequences for the 18s rRNA phylogeny were aligned using the SINA Webaligner http://www.arb-silva.de/ aligner, which aligns them in accordance with the ARB/ SILVA rRNA alignment [38] which is based on a secondary structure model [39]. Subsequently we used Gblocks [40] to identify reliably aligned parts, using the default settings except that we did not require the coverage for every position to be $100 \%$, but rather $80 \%$. We then used PhyML v3.0.1 (HKY85 model, optimised equilibrium frequencies, estimated ts/tv ratio, estimated proportion of invariable sites, 4 substitution rate categories, estimated gamma distribution parameter, NNI tree topology search, 100 bootstrap iterations [41]) to obtain the phylogeny.

The genetic code used for the translation of the Euplotes mitochondrial DNA was derived using the standard genetic code for translation of the complete DNA sequence in 6 frames, and searching the resulting protein sequences for conserved Pfam-fs protein domains [42] using HMMPFAM [30]. The amino acid frequencies provided by the Pfam HMM profiles were then used to predict the translation of each codon. Averaging over all aligned occurrences of the codon, the highest scoring (i.e. most often aligned) amino acid was predicted to be the translation of the codon in vivo.

\section{Authors' contributions}

RdG participated and coordinated cloning, sequencing and analyzing of both mitochondrial genomes and drafted the manuscript. BD analyzed the genetic code and performed the bioinformatic analysis. TvA participated in sequencing and analyzing the mitochondrial genomes. HvZ and MBH cloned and sequenced parts of the mitochondrial genome of Euplotes crassus. JK participated in cloning, sequencing and analyzing the mitochondrial genome of Euplotes minuta. HDG cultivated Euplotes minuta and provided cells for PFGE. MH supervised sequence analysis and participated in drafting the manuscript. JH initiated and coordinated the study and participated in drafting the manuscript. All authors read and approved the final version of the manuscript. 


\section{Additional material}

\section{Additional file 1}

Figure S1. Multiple sequence alignment of the N-terminal part of Cox1. Click here for file

[http://www.biomedcentral.com/content/supplementary/1471-

2164-10-514-S1.pdf]

\section{Additional file 2}

Figure S2. Multiple sequence alignment of the C-terminal part of Cox1. Click here for file

[http://www.biomedcentral.com/content/supplementary/1471-

2164-10-514-S2.pdf]

\section{Additional file 3}

Figure S3. Multiple sequence alignment of the C-terminal part of the ribosomal protein S3.

Click here for file

[http://www.biomedcentral.com/content/supplementary/14712164-10-514-S3.pdf]

\section{Additional file 4}

Protein identifiers. Accession numbers of mitochondrion-encoded proteins.

\section{Click here for file}

[http://www.biomedcentral.com/content/supplementary/14712164-10-514-S4.doc]

\section{Acknowledgements}

This work was partially suported by the European Union 5th framework grant 'CIMES' (QLK3-2002-02I5I).

\section{References}

I. Pritchard AE, Seilhamer J, Mahalingam R, Sable CL, Venuti SE, Cummings DJ: Nucleotide sequence of the mitochondrial genome of Paramecium. Nucleic Acids Res 1990, I 8(I): I73-180.

2. Moradian MM, Beglaryan D, Skozylas JM, Kerikorian V: Complete Mitochondrial Genome Sequence of Three Tetrahymena Species Reveals Mutation Hot Spots and Accelerated Nonsynonymous Substitutions in Ymf Genes. PLOS ONE 2007, 2(7):.

3. Brunk CF, Lee LC, Tran AB, Li J: Complete sequence of the mitochondrial genome of Tetrahymena thermophila and comparative methods for identifying highly divergent genes. Nucleic Acids Res 2003, 3 I (6): I673-1682.

4. Burger G, Zhu Y, Littlejohn TG, Greenwood SJ, Schnare MN, Lang BF, Gray MW: Complete sequence of the mitochondrial genome of Tetrahymena pyriformis and comparison with Paramecium aurelia mitochondrial DNA. J Mol Biol 2000, 297(2):365-380.

5. Jurland A, Lipps HJ: Two types of mitochondria in Euplotes minuta. Arch Protistenk Bd 1973, I I 5, S: I33-I36.

6. Görtz HD: Untersuchungen zur Feinstruktur von Euplotes minuta Yocum (Ciliata, Hypotrichida) unter besonderer Berücksichtigung von Cortexstrukturen. In PhD thesis Münster: University of Münster; 1975.

7. Ricard G, de Graaf RM, Dutilh BE, Duarte I, van Alen TA, van Hoek AH, Boxma B, Staay GW van der, Staay SY Moon van der, Chang WJ, et al:: Macronuclear genome structure of the ciliate Nyctotherus ovalis: Single-gene chromosomes and tiny introns. BMC Genomics 2008, 9(I):587.

8. Boxma B, Ricard G, van Hoek AH, Severing E, Staay SY Moon-van der, Staay GW van der, van Alen TA, de Graaf RM, Cremers G, Kwantes $M$, et al.: The [FeFe] hydrogenase of Nyctotherus ovalis has a chimeric origin. BMC Evol Biol 2007, 7:230.
9. Akhmanova A, Voncken F, van Alen T, van Hoek A, Boxma B, Vogels $G$, Veenhuis $M$, Hackstein JH: A hydrogenosome with a genome. Nature I998, 396(67 I I):527-528.

10. Boxma B, de Graaf RM, Staay GW van der, van Alen TA, Ricard G, Gabaldon T, van Hoek AHAM, Staay SY Moon-van der, Koopman W], van Hellemond JJ, et al.: An anaerobic mitochondrion that produces hydrogen. Nature 2005, 434(7029):74-79.

II. Morin GB, Cech TR: Mitochondrial telomeres: surprising diversity of repeated telomeric DNA sequences among six species of Tetrahymena. Cell 1988, 52(3):367-374.

12. Morin GB, Cech TR: Telomeric repeats of Tetrahymena malaccensis mitochondrial DNA: a multimodal distribution that fluctuates erratically during growth. Mol Cell Biol 1988, 8(1 0):4450-4458.

13. Gupta S, Stamatoyannopoulos JA, Bailey TL, Noble WS: Quantifying similarity between motifs. Genome Biol 2007, 8(2):R24.

14. Lazdins I, Cummings D: Structural and functional analysis of the origin of replication of mitochondrial DNA from Paramecium aurelia. Curr Genet 1984, 8:483-487.

15. Kiss GB, Amin AA, Pearlman RE: Two separate regions of the extrachromosomal ribosomal deoxyribonucleic acid of Tetrahymena thermophila enable autonomous replication of plasmids in Saccharomyces cerevisiae. Mol Cell Biol 198I, I(6):535-543.

16. Pritchard AE, Laping JL, Seilhamer JJ, Cummings DJ: Inter-species sequence diversity in the replication initiation region of Paramecium mitochondrial DNA. J Mol Biol I983, I64(I): I-I5.

17. Hauth AM, Maier UG, Lang BF, Burger G: The Rhodomonas salina mitochondrial genome: bacteria-like operons, compact gene arrangement and complex repeat region. Nucleic Acids Res 2005, 33( I 4):4433-4442.

18. Kim E, Lane CE, Curtis BA, Kozera C, Bowman S, Archibald JM: Complete sequence and analysis of the mitochondrial genome of Hemiselmis andersenii CCMP644 (Cryptophyceae). BMC Genomics 2008, 9:215.

19. Thompson JD, Higgins DG, Gibson TJ: CLUSTAL W: improving the sensitivity of progressive multiple sequence alignment through sequence weighting, position-specific gap penalties and weight matrix choice. Nucleic Acids Res 1994, 22(22):4673-4680.

20. Waterhouse AM, Procter JB, Martin DM, Clamp M, Barton GJ: Jalview Version 2 - a multiple sequence alignment editor and analysis workbench. Bioinformatics 2009, 25(9): | |89-9|.

21. Edgar RC: MUSCLE: multiple sequence alignment with high accuracy and high throughput. Nucleic Acids Res 2004, 32(5): $1792-1797$.

22. Finn RD, Tate J, Mistry J, Coggill PC, Sammut SJ, Hotz HR, Ceric G, Forslund K, Eddy SR, Sonnhammer EL, et al.: The Pfam protein families database. Nucleic Acids Res 2008:D28I-288.

23. Claros MG, Vincens P: Computational method to predict mitochondrially imported proteins and their targeting sequences. Eur J Biochem 1996, 24 I(3):779-786.

24. Ueda M, Fujimoto M, Arimura S, Tsutsumi N, Kadowaki K: Presence of a latent mitochondrial targeting signal in gene on mitochondrial genome. Mol Biol Evol 2008, 25(9): I79|-I793.

25. Huynen MA: Presence of a latent mitochondrial targeting signal in gene on mitochondrial genome Faculty Comments \& Author Responses. Faculty of 1000 Biology 2009 [http://
[ent fl000biology.com/article/id/ I 158887/evaluation].

26. Small I, Peeters N, Legeai F, Lurin C: Predotar: A tool for rapidly screening proteomes for $\mathbf{N}$-terminal targeting sequences. Proteomics 2004, 4(6): I 58I- I 590.

27. Emanuelsson O, Brunak S, von Heijne G, Nielsen H: Locating proteins in the cell using TargetP, SignalP and related tools. Nat Protoc 2007, 2(4):953-97I.

28. Gray MW, Lang BF, Cedergren R, Golding GB, Lemieux C, Sankoff D, Turmel M, Brossard N, Delage E, Littlejohn TG, et al.: Genome structure and gene content in protist mitochondrial DNAs. Nucleic Acids Res 1998, 26(4):865-878.

29. Turanov AA, Lobanov AV, Fomenko DE, Morrison HG, Sogin ML, Klobutcher LA, Hatfield DL, Gladyshev VN: Genetic code supports targeted insertion of two amino acids by one codon. Science 2009, 323(59I I):259-26I.

30. Soding J: Protein homology detection by HMM-HMM comparison. Bioinformatics 2005, 2 I (7):951-960. 
31. Smith TF, Waterman MS: Identification of common molecular subsequences. J Mol Biol I98I, I47(I): 195-197.

32. Nosek J, Tomaska L, Fukuhara H, Suyama Y, Kovac L: Linear mitochondrial genomes: 30 years down the line. Trends Genet 1998, 14(5): $184-188$.

33. Feagin JE: The extrachromosomal DNAs of apicomplexan parasites. Annu Rev Microbiol 1994, 48:8I-104.

34. Hall TA: BioEdit: a user-friendly biological sequence alignment editor and analysis program for Windows 95/98/NT. Nucl Acids Symp Ser 1999, 41:95-98.

35. Laslett $D$, Canback B: ARAGORN, a program to detect tRNA genes and tmRNA genes in nucleotide sequences. Nucleic Acids Res 2004, 32(1): II-16.

36. Altschul SF, Madden TL, Schaffer AA, Zhang J, Zhang Z, Miller W, Lipman DJ: Gapped BLAST and PSI-BLAST: a new generation of protein database search programs. Nucleic Acids Res 1997, 25(17):3389-3402.

37. Larkin MA, Blackshields G, Brown NP, Chenna R, McGettigan PA, McWilliam H, Valentin F, Wallace IM, Wilm A, Lopez R, et al.: Clustal W and Clustal X version 2.0. Bioinformatics 2007, 23(2I):2947-2948.

38. Pruesse E, Quast C, Knittel K, Fuchs BM, Ludwig W, Peplies J, Glockner FO: SILVA: a comprehensive online resource for quality checked and aligned ribosomal RNA sequence data compatible with ARB. Nucleic Acids Res 2007, 35(21):7188-7196.

39. Gutell RR, Larsen N, Woese CR: Lessons from an evolving rRNA: 16S and 23S rRNA structures from a comparative perspective. Microbiol Rev 1994, 58(1):10-26.

40. Castresana J: Selection of conserved blocks from multiple alignments for their use in phylogenetic analysis. Mol Biol Evol 2000, I 7(4):540-552.

4I. Guindon S, Gascuel O: A simple, fast, and accurate algorithm to estimate large phylogenies by maximum likelihood. Syst Biol 2003, 52(5):696-704.

42. Bateman A, Birney E, Cerruti L, Durbin R, Etwiller L, Eddy SR, Griffiths-Jones S, Howe KL, Marshall M, Sonnhammer EL: The Pfam protein families database. Nucleic Acids Res 2002, 30(I):276-280.

Publish with Bio Med Central and every scientist can read your work free of charge

"BioMed Central will be the most significant development for disseminating the results of biomedical research in our lifetime. "

Sir Paul Nurse, Cancer Research UK

Your research papers will be:

- available free of charge to the entire biomedical community

- peer reviewed and published immediately upon acceptance

- cited in PubMed and archived on PubMed Central

- yours - you keep the copyright
BioMedcentral 